\title{
Romatizmal Hastalıklarda Tamamlayıcı ve Alternatif Tıp Yöntemlerine Başvuru
}

\author{
Application of Complementary and Alternative Medicine Methods in Rheumatic Diseases
}

\section{Özlem SOLAK' ${ }^{1}$ Alper Murat ULAŞLI ${ }^{1}$, Halime ÇEVIK ${ }^{1}$, Aylin DiKiCi' ${ }^{2}$, Gül DEVRIMSEL ${ }^{3}$, Esra ERKOL INAL ${ }^{4}$,

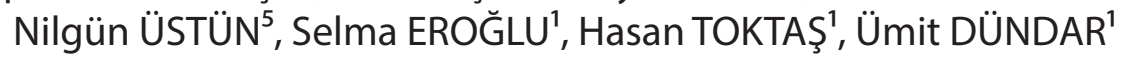

\author{
${ }^{1}$ Kocatepe Üniversitesi Tıp Fakültesi Fiziksel Tıp ve Rehabilitasyon AD, Afyonkarahisar \\ ${ }^{2}$ Afyonkarahisar Devlet Hastanesi Fiziksel Tıp ve Rehabilitasyon Kliniği, Afyonkarahisar \\ ${ }^{3}$ Recep Tayyip Erdoğan Üniversitesi Tıp Fakültesi Fiziksel Tıp ve Rehabilitasyon AD, Rize \\ ${ }^{4}$ Süleyman Demirel Üniversitesi Tıp Fakültesi Fiziksel Tıp ve Rehabilitasyon AD, Isparta \\ ${ }^{5}$ Mustafa Kemal Üniversitesi Tıp Fakültesi Fiziksel Tıp ve Rehabilitasyon AD, Hatay
}

Geliş Tarihi / Received: 21.02.2014

\section{ÖZET}

\begin{abstract}
Amaç: İnflamatuar romatizmal hastalıklar kronik multisistemik hastalıklardır ve başlıcaları Romatoid Artrit (RA) ve Ankilozan Spondilit (AS)'tir. Bu hastalıklarda etkin tedaviler bulunmasına karşın, hastalar tamamlayıcı ve alternatif tıp (TAT) yöntemlerine de başvurabilmektedirler. Bu çalışmadaki amacımız RA ve AS hastalarının TAT yöntemlerine başvuru sıklığını, nedenlerini ve bu hastaların fayda görüp görmediklerini saptamaktır.
\end{abstract}

Gereç ve Yöntem: Çalışmaya FizikselTıp ve Rehabilitasyon kliniklerine başvuran RA ve AS tanısı alan 391 hasta dahil edildi. Hastalara'Romatizmal Hastalığı Bulunan Hastaların TAT Yöntemlerine Başvurma Sıklığı ve Nedenleri' anketi uygulandı.

Bulgular: Toplamda 211 RA ve 180 AS hastası çalışmaya alındı. 120 hasta TAT yöntemine başvurmuştu (69 RA, 51 AS). 100 hasta ağrı nedeni ileTAT'a başvururken, başvurma kararında büyük oranda çevre etkiliydi. Hastaların yaklaşık yarısı tanı konmadan önce TAT kullanmışlardı ve Afyonkarahisar şehrinde yaşayan hastalar diğer şehirlere göre daha fazla oranda TAT'a başvurmuşlardı. En sık kullanılan TAT yöntemleri bitkisel yöntemler ve şifalı sular olarak saptandı. Hastaların yaklaşık yarısı kullandığı yöntemden fayda görmezken, 14 hasta zarar gördüğünü bildirdi.

Sonuç: Birçok kronik hastalıkta olduğu gibi RA ve AS hastalarında da TAT başvurusu giderek artmaktadır. TAT yöntemine başvurma sıklığı ve TAT yöntemleri halkın kültürüne göre değişiklik gösterebilmektedir. Klinisyenlerin bu hastaların TAT yöntemi kullanabileceğini göz önünde bulundurmaları ve TAT yöntemlerinin olası yan etkileri hakkında bilgi sahibi olmaları gerekmektedir.

Anahtar Kelimeler: Romatoid artrit; ankilozan spondilit; tamamlayıcı ve alternatif tıp.
Kabul Tarihi / Accepted: 10.04.2014
Objective: Although there areeffective treatmentsforrheumatic diseases, patientsmay appeal for complementary and alternative medicine (CAM) methods. The aim ofthis studyis to determine CAM method referencefrequency, causes, andwhether patients with a diagnosis of Rheumatoid arthritis (RA) or Ankylosing spondylitis (AS) had benefit or not.

Material and Methods: 391 patients who were admitted to Physical Medicine and Rehabilitation clinics and diagnosed withRA andAS were included. All patients filled 'The frequency and reasons for applying CAM methods in patients with rheumatic diseases' questionnaire.

Results: A total of 211RA and180AS patients were included. 120 patients experienced a CAM method at least one time (69RA,51AS). 100 of them used CAM method because of pain. The patients were mostly influenced bysocial circle while giving decision to use a CAM. About half ofthe patients experienced CAM before diagnosis and patients living in Afyonkarahisar used CAM therapies more frequentlythan other cities. The most commonly used CAM methods were herbal methods and mineral springs. About half of the patients didn't benefit from the method they used. Moreover, 14 patients found CAM harmful.

Conclusion: As inmany chronic diseases, patients withRA and ASincreasingly use CAM methods. CAM therapies and frequency of CAM therapy applications may varydue tocultural aspects of the patients. Clinicians should be aware of the fact that the patients may use CAM therapies and inform the patient about their possible side effects.

Keywords: Rheumatoid arthritis; ankylosing spondylitis; complementary and alternative medicine. 


\section{Giriş̧}

Romatizmal hastalıklar remisyon ve akut ataklarla seyreden, klinik seyir ve bulgularda farklılık gösteren kronik multi-sistem hastalıklardır (1). Hastalarda ağrı ve fiziksel engellilik oluşturarak yaşam kalitesini olumsuz etkileyebilmektedir $(2,3)$. Ankilozan Spondilit (AS) ağırlıklı olarak aksiyel iskeleti tutar iken, Romatoid Artrit (RA) ise sıklıkla periferik eklemlerin kronik sinoviti ile karakterizedir. Her iki hastalıkta da tedavi küratif değildir, amaç hastalığın bulgularının azaltılmasıdır. Bu hastalıklarda geleneksel tedavi yöntemleri (steroid olmayan anti-inflamatuarlar, hastalık modifiye edici anti-romatizmal ilaç (HMEARi), biyolojik ajanlar, fizik tedavi ve rehabilitasyon programları, cerrahi tedavi) günümüzde başarılı bir şekilde uygulanmaktadır (1). Bununla birlikte, geleneksel tedaviler bazen hastalara tatmin edici bir etkinlik sunamamaktadır (3). Bu nedenle son dönemde pek çok kronik hastalıkta olduğu gibi romatizmal hastalıklarda da kronik doğası ve yaşam kalitesi üzerine etkileri nedeni ile bu klasik tedavi yöntemlerinin yanı sıra tamamlayıcı ve alternatif tıp (TAT) yöntemleri adı altında bir grup destekleyici tedavi yöntemi de kullanılmaya başlanmıştır $(4,5)$. TAT konvansiyonel tedaviler içinde yer almayan, etkinliğinin ve fonksiyonunun kanıtları halen yetersiz olan çeşitli uygulamalardan oluşmaktadır (6). TAT kullanımı ve popülaritesi dünya çapında giderek artış göstermektedir (7). Bitkisel ilaçların tanıtımı, medya, internet siteleri, popüler kitaplar ve ünlüler tarafından yoğun bir şekilde kullanılması, bitkisel ilaçlara erişimin kolay olması ve genellikle besin desteği olarak pazarlanabilmesi, etkinliklerine ilişkin abartılı iddiaların öne sürülmesi ilgiyi daha da artırmıştır (1).

Amerika Birleşik Devletleri'nde bulunan ulusal tamamlayıcı ve alternatif tıp merkezi (NCCAM) tarafından TAT; 'şu an için konvansiyonel tıbbın bir parçası sayılmayan ancak tıbbın çeşitli alanlarında ve sağlık bakım sisteminde yer alan uygulama ve ürünler' olarak tanımlanmaktadır (8). TAT 5 grupta sınıflandırılmıştır: 1-Biyoloji-temelli tedaviler (diyet, doğal ürüntakviyelerivebitkisel tedavi), 2-Manipülatifvevücuttemelli uygulamalar (masaj, manuel terapi), 3-Zihin-beden uygulamaları (meditasyon, yoga, gevşeme terapisi, nefes teknikleri, biofeedbackvehipnoz), 4-
Enerji terapileri (dua, reiki), 5-Medikal sistemler (7). Kullanılan yöntemler eğitim düzeyine, sosyoekonomik faktörlere, dini inanışlara, yaşam şekillerine ve kültürlere göre farklılıklar göstermektedir (1).Bu çalışmadaki amacımız RA ve AS gibi romatizmal hastalığı olan kişilerde TAT yöntemi başvuru sıklığı, TAT kullanmaya sevk eden sebeplerin neler olduğu, bunun yanı sıra hastaların TAT yöntemlerinden ne kadar fayda gördüğünü saptamaktır.

\section{GEREÇ ve YÖNTEM}

Çalışma Afyon Kocatepe Üniversitesi, Isparta Süleyman Demirel Üniversitesi, Hatay Mustafa Kemal Üniversitesi ve Rize Recep Tayyip Erdoğan Üniversitesi Tıp Fakültesi Fiziksel Tıp ve Rehabilitasyon kliniklerinde Mayıs 2013-Eylül 2013 tarihleri arasında gerçekleştirildi. Afyon Kocatepe Üniversitesi Tıp Fakültesi Bilimsel Araştırmalar Etik Kurulundan onay alındı. Çalışmaya 18-75 yaş arası, daha önce RA ve AS tanısı alan, anket sorularını cevaplayabilecek bilişsel yetiye sahip olan hastalar alındı. Cinsiyet farklılığı gözetilmedi. RA ve AS dışındaki romatizmal hastalığı bulunan hastalar çalışmadan dışlandı. Çalışma, hastalara TAT kullanımı hakkında bilgi edinme taraması olarak tanıtıldı. Hastalardan görüşme yapmak üzere bilgilendirilmiş yazılı onam alındıktan sonra 'Romatizmal Hastalığı Bulunan Hastaların Tamamlayıcı ve Alternatif Tıp (TAT) Yöntemlerine Başvurma Sıklığı ve Nedenleri' başlıklı anket formu doldurmaları istendi. Bu anket formu tarafımızca Amerika Birleşik Devletleri NCCAM'nin resmi internet sitesinde yer alan tanımlara göre düzenlenmiştir. Hastaların ad, soyad, yaş, cinsiyet, eğitim durumu gibi sosyo-demografik bilgileri ve hastalığı, hastalık aktivitesi, romatolojik hastalığı ile ilgili kullandığı ilaç bilgileri değerlendirildi. Hastalık aktivitesi RA hastaları için Disease Activity Score-28 (DAS-28) ile AS hastaları için Bath Ankylosing Spondylitis Disease Activity Index (BASDAI) ile hesaplandı. Kullanılan ilaçlar HMEARI ve biyolojik ajan olarak iki gruba ayrılıp değerlendirmeye alındı. Hastalara TAT yöntemlerine başvurup başvurmadığı, başvurdu ise hangi yönteme başvurduğu, başvurma nedeni, kullanma kararını nasıl verdiği (kendisi, aile, çevre, medya, internet, doktor...), fayda görüp görmediği, fayda gördü ise ne düzeyde faydalandığı (çok fayda 
görme, fayda görme, biraz fayda görme, hiç fayda görmeme, zarar görme), ailede TAT kullanımı ve yan etki gibi maddeler içeren anket uygulandı. Hastaların TAT yöntemine romatizma polikliniğine başvurup tanı konmadan önce mi sonra mı başvurdukları incelendi. TAT yöntemleri olarak bitkisel yöntemler, kurşun döktürme, türbe ziyareti-okutma, muska-büyü yaptırma, balık, sülük, yün sarma-ip bağlama, çeşitli cihaz kullanma, masaj, yoga, meditasyon, akupunktur, kırıkçı-çıkıkçıya gitme, şifalı sulara gitme, kupa basma ve diğer yöntemler ayrı ayrı sorgulandı. Hastalardan elde edilen veriler SPSS istatistik programı ile analiz edildi.

\section{BULGULAR}

Çalışmaya toplam 391 hasta dahil edildi. Dahil edilen hastaların sosyo-demografik verileri Tablo I'de gösterilmektedir. Hastaların TAT başvuru sıklığı, başvuru nedenleri, TAT kullanma kararını nasıl verdiği, ailede TAT kullanma öyküsü, tanı konmadan önce başvurma sıklığı ve tedaviden gördükleri fayda miktarı Tablo II'de gösterilmektedir. AS ve RA hastalarının \%30,8'inin TAT yöntemlerinden herhangi birine başvurduğunu saptadık. Kullanılan TAT yöntemlerinin sayı ve yüzdeleri Şekil I'de görülmektedir. 10 hasta birden fazla TAT yöntemi kullanmıştır.

Tablo I: Hastalara ait sosyo-demografik veriler.

\begin{tabular}{ll}
\hline & Sayı (Yüzde) \\
\hline Hasta Sayısı (RA/AS) & 211 (\% 54)/180 (\% 46) \\
Cinsiyet (Bayan/Erkek) & $230(\% 58,8) / 161(\% 41,2)$ \\
Yaş Ortalaması (Yıl) & $45,9 \pm 12,9$ \\
Eğitim Süresi Ortalaması (Yıl) & $5 \pm 1$ \\
Kullandığı Illaç (HMEARi/BA) & $234(\% 59,8) / 157(\%$ 40,2) \\
Yaşadığı Şehire Göre Hasta Sayıları & $180(\%$ 46) / $46(\%$ 11,8) / $96(\%$ 24,6) / $69(\%$ 17,6) \\
(Afyon/lsparta/Hatay/Rize) & \\
\hline
\end{tabular}

RA: Romatoid Artrit, AS: Ankilozan Spondilit, HMEARi: Hastalık Modifiye Edici Antiromatizmal İlaç, BA: Biyolojik Ajan.

Tablo II: TAT anket sonuçları.

\begin{tabular}{|c|c|}
\hline & Sayı (Yüzde) \\
\hline $\begin{array}{l}\text { TAT Başvuru sıklığı } \\
\text { (RA/AS) }\end{array}$ & $69(\%$ 32,7) / 51 (\% 28,3) \\
\hline Başvuru Nedeni & $\begin{array}{l}\text { Ağrı } 100(\% \text { 83,3) } \\
\text { Şişlik } 19 \text { (\% 15,8) } \\
\text { Tutukluk } 1(\% 0,8)\end{array}$ \\
\hline Kullanma Kararı & $\begin{array}{l}\text { Çevre } 53 \%(44,2) \\
\text { Kendisi } 23(\% 19,2) \\
\text { Aile } 20(\% 16,7) \\
\text { Medya } 14(\% 11,7) \\
\text { İnternet } 5(\% 4,2) \\
\text { Doktor } 5(\% 4,2) \\
\end{array}$ \\
\hline Ailede TAT kullanma öyküsü & $16(\% 8)$ \\
\hline Tanı Konmadan Önce TAT Başvuru & $67(\% 55,8)$ \\
\hline Gördüğü fayda miktarı & $\begin{array}{l}\text { Çok fayda gördüm } 4 \text { (\% 3,3) } \\
\text { Fayda fördüm } 14 \text { (\% 11,7) } \\
\text { Biraz fayda gördüm } 34 \text { (\% 28,3) } \\
\text { Fayda görmedim } 54(\% \text { 45) } \\
\text { Zarar gördüm } 14(\% 11,7)\end{array}$ \\
\hline
\end{tabular}

TAT: Tamamlayıcı ve Alternatif Tıp, RA: Romatoid Artrit, AS: Ankilozan Spondilit. 


\section{Hasta Sayısı}

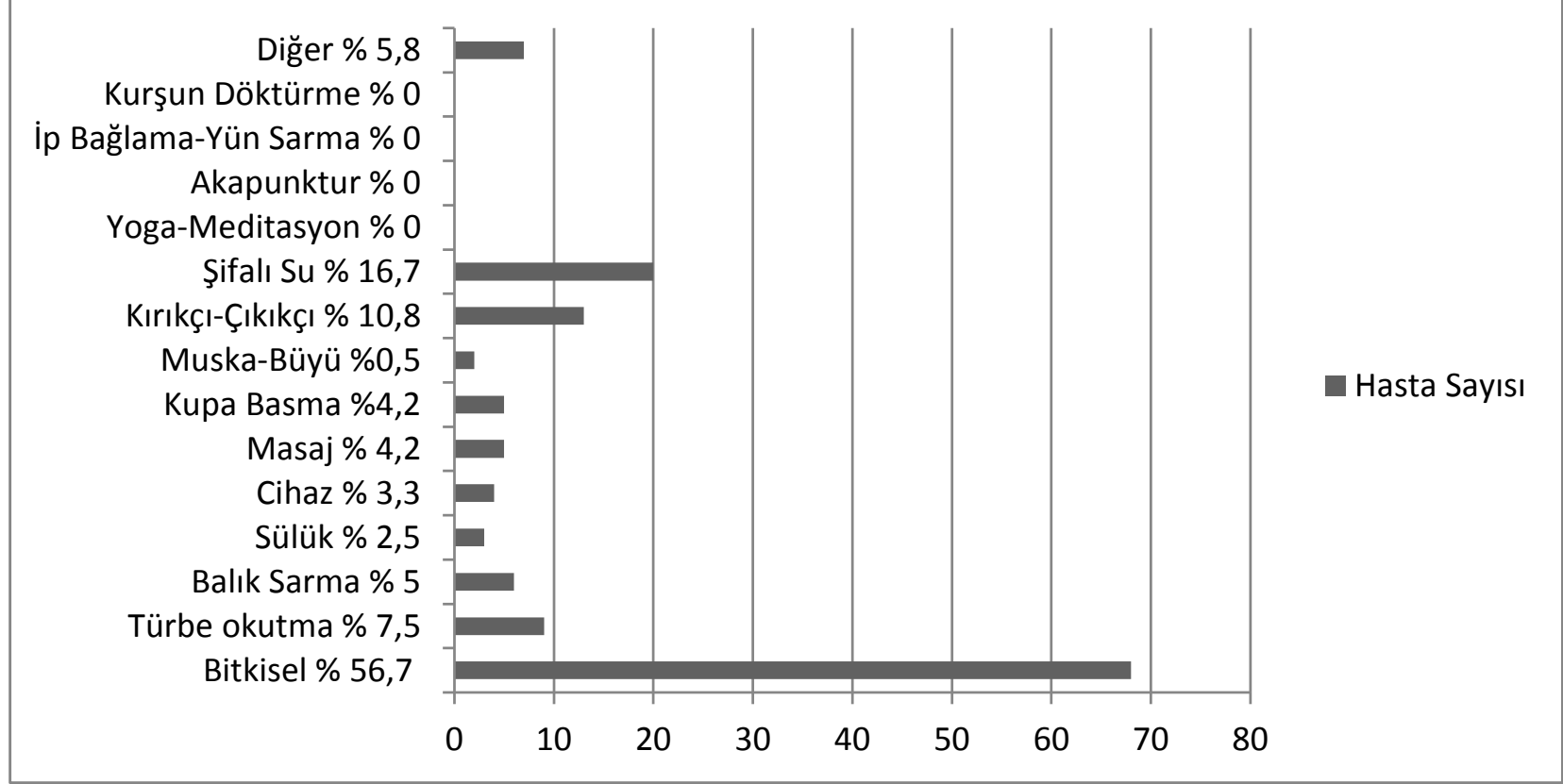

Şekil ı: TAT yöntemleri sayı ve yüzdeleri(TAT: Tamamlayıcı ve Alternatif Tıp).

Toplam 211 RA hastasının 69'u $(\% 32,7)$ TAT yöntemi kullanırken, 51(\%28,7) AS'li hasta TAT kullanmaktaydı. Hastalık tanısına göre TAT yöntemine başvurma sıklığı arasında anlamlı fark saptanmadı $(p>0,05)$. Erkek hastaların 41 i $(\% 30,6)$ TAT yöntemi kullanırken, bayanların 71 i (\%31) TAT a başvurmuştu. Cinsiyete göre TAT başvurusu arasında fark saptanmadı $(p=0,937)$. Yaş ve TAT başvuru arasında da istatistiksel olarak ilişki saptanmadı $(p=0,794, r=0,090)$.

Hastalık aktivitesi ile TAT başvurusu arasındaki ilişki değerlendirildiğinde, RA'da anlamlı ilişki saptanmaz iken $(p=0,535), A S^{\prime}$ de hastalık aktivitesi arttıkça TAT başvurma sıklığının arttığı saptandı. Bu pozitif ilişki istatiksel olarak anlamlı, fakat zayıf idi $(p=0,013 \quad r=0,287)$. HMEARi kullanan hastaların 72'si $(\% 30,9)$ ve biyolojik ajan kullananların 48'i $(\% 30,8)$ TAT yöntemine başvurmuştu. Kullandığı ilaca göre TAT başvurusu değerlendirildiğinde fark saptanmadı $(p=0,978)$.

Yaşadığı şehir açısından bakıldığında, Afyon'da yaşayan hastaların 77'si (\%42,8), Isparta'da yaşayanların 12'si $(\% 26,1)$, Hatay'da yaşayanların 17 'si $(\% 17,7)$, Rize'de yaşayanların 14'ü $(\% 20,9)$ TAT yöntemine başvurmuştu. Afyon'da yaşayan hastalarda TAT yöntemine başvuru oranı diğer şehirlerden anlamlı derecede yüksekti, fakat diğer şehirler arasında farklılık yoktu (AfyonHatay $p<0,001$, Afyon-Isparta $p=0,039$, AfyonRize $p=0,002)$. Hastaların TAT yöntemlerinden fayda görme düzeyleri iki romatizmal hastalıkta da benzerdi ( $p>0.05)$.

\section{TARTIŞMA}

Daha önce farklı ülkelerde yapılan çalışmalarda, artrit hastalarında TAT kullanma sıklığı \%33 ile \%66 arasında olduğu bildirilmiştir (9-15). RA'ı Japon hastalarda TAT kullanım sıklığı \%35 iken (16), yakın zamanda Ulusoy ve ark.'nın yaptığı yeni bir çalışmada ise Türk romatolojik hastaların yaklaşık yarısı (\%46.2) en az bir TAT yöntemini tecrübe ettiği bildirilmiştir (2). Kore'li RA hastalarında yapılan bir çalışmada bu oran \%82 olarak bulunmuştur (6). Bu çalışmada ülkemizde TAT kullanımının daha düşük sıklıkta saptanmasının nedeni kültürel farklılıklar olabileceği gibi hastaların hekimden çekinmeleri nedeni ile TAT kullandıklarını gizlemeleri de olabilir.

Önceki çalışmalara göre, TAT yöntemleri ülkelere ve kültürlere göre değişmektedir $(6,15,16)$. Bu farklılıklar coğrafi, etnik veya hastalık özelliklerinden ziyade büyük oranda halk tıbbının özelliklerine, popüler TAT tedavilerine ve TAT 
uygulayıcılarının erişilebilirliğine bağlıdır. Genel anlamda, romatizma hastaları tarafından en çok kullanılan TAT yöntemleri akupunktur, masaj, bitkiler ve homeopatidir $(1,16)$. Ülkemizde yapılan çalışmalarda en sık kullanılan TAT yöntemlerinin bitkisel kaynaklı ve beslenme değişiklikleri olduğu, diğer yöntemlerin ise vücut temelli uygulamalar, dua, dini uygulamalar, masaj, vitaminler ve özel diyetler olduğu saptanmıştır $(1,2)$. Aynı ülkede bile farklı şehirlerde TAT başvuru sıklığı ve yöntemleri değişebilmektedir. Çalışmadaki bulgulara göre ise en sık başvurulan TAT yöntemi bitkisel ürünler iken $(\% 56,7)$, bunu şifalı sular $(\% 16,7)$ takip etmektedir.

Afyonkarahisar şehrinde TAT başvuru sıklığı Isparta, Hatay ve Rize şehirlerinde yaşayan RA ve $A S^{\prime}$ li hastalara göre daha yüksek iken diğer şehirlerarasında fark bulunamadı. Bu sonuç geçmiş çalışmalardaki TAT başvuru sıklığı ve yöntemlerinin kültürden etkilenmekte olduğu bilgisini desteklemektedir (17). Bununla birlikte, Afyonkarahisar şehrinin şifalı sular için merkezi bir yerde bulunması, daha fazla hastanın şifalı sulardan yararlanması TAT başvuru sıklığının diğer şehirlerden yüksek olmasının önemli bir nedeni olabilir.

Mevcut çalışmada, geçmiş çalışmalardaki bulgulara paralel bir şekilde, hastaların büyük kısmı ağrının giderilmesi beklentisi ile TAT yöntemine başvurdukları saptanmıştır $(6,16,18)$. Diğer bir sık neden ise eklem şş̧liğidir. TAT kullanımı romatizmal hastalarda çok çeşitli nedenlerin etkisiyle başlanmaktadır. Çevre etkisi ile, doktor önerisi ile ya da medyadan etkilenerek karar verilebilmektedir. Önceki çalışmalarda hastaların yarısı TAT kullanma kararını çevresinden etkilenerek verdiği bildirilmiştir $(1,19)$. Benzer olarak, bizim çalışmamızda da TAT yöntemine başvuran hastaların yarısı kullanma kararını çevre etkisi ile vermişti ve klinisyenlerin önerisiyle TAT kullanan hasta sayısı oldukça azdı.

Önceki çalışmalarda TAT yöntemlerine başvuran hastalarda fayda görme oranı genelde \%25 gibi düşük seviyelerde idi (2). Buna ek olarak yan etki görülme sıklığı bir çalışmada \%5,5 idi (1). Çalışmamızda hastaların yarısından fazlası fayda görmediğini, üstelik \%14'ü kullandığı
TAT yönteminden zarar gördüğünü bildirmiştir. Gabriel ve ark.'ı İsrail'de ve Karadağ ve ark.'ı ülkemizde yaptıkları çalışmalarda eğitim düzeyi arttıkça TAT başvuru sıklığının arttığını bildirmişlerdir $(1,19)$. Buna karşın Ramos ve ark' nın yaptığı başka bir çalışmada ise eğitim düzeyi düştükçe TAT kullanım sıklığının arttığı bildirilmiştir (18). Mevcut çalışmada, TAT başvurusu ve eğitim düzeyi arasında bir ilişki saptanmaz iken, farklı şehirlerarasında eğitim düzeyleri arasında da farklılık saptanmadı.

Kanada'da yapılan bir çalışmada TAT kullanan hastaların \%47'si bir romatoloğa başvurmadan önce en az bir kez TAT kullanmıştı (18). Bizim çalışmamızda da TAT kullananların \%55,8'i romatizma polikliniğine başvurup tanı konmadan önce TAT denemişlerdi. Hastaların önemli bir kısmının henüz hastalıklarının tanısı konulmadan alternatif tedaviye yönelmeleri, hastaların TAT kullanmayı tercih etmesinde RA ve AS gibi romatizmal hastalıkların tedavisindeki yetersizlikler yerine, daha başka sebeplerin rol oynadığını düşündürmektedir.

Sonuç olarak diğer birçok kronik hastalıkta olduğu gibi RA ve AS tedavisinde de yakın zamanda ciddi ilerlemeler kaydedilmiş olmasına karşın alternatif tıp yöntemlerine başvuru giderek artmaktadır. TAT yöntemine başvurma sıklığı ve TAT yöntemleri halkın kültürüne, alışkanlıklarına ve TAT yönteminin erişebilirliğine göre değişiklik gösterebilmektedir. Romatizmal hastalıklarla ilgilenen klinisyenlerin bu hastaların TAT yöntemi kullanabileceğini göz önünde bulundurmaları, TAT yöntemlerinin potansiyel zararları hakkında bilgi sahibi olmaları ve hastaları doğru yönlendirmeleri gerekmektedir.

\section{KAYNAKLAR}

1. Karadağ A. Romatizmal hastalıklarda alternatif tıp ve tamamlayıcı tedavi yöntemleri. Uzmanlık Tezi. Sivas: Cumhuriyet Üniversitesi Tıp Fakültesi, Fiziksel Tıp ve Rehabilitasyon Anabilim Dalı, 2012.

2. Ulusoy $H$, Güçer TK ,Aksu M, et al. The use of complementary and alternative medicine in Turkish patients with rheumatic diseases. Turk J Rheumatol 2012;27(1):31-7. 
3. Álvarez-Hernández E, Casasola-Vargas JC, Lino-Pérez L, Burgos-Vargas R, Vázquez-Mellado J. Complementary and alternative medicine in patients attending a rheumatology department for the firsr time analysis of 800 patients. Reumatol Clin 2006;2(4):183-9.

4. Silva VD, El-Metwally A, Ernst E, Lewith G, Macfarlane GJ. Evidence for the efficacy of complementary and alternative medicines in the management of rheumatoid arthritis: a systematic review. Rheumatology 2011;50(9):1672-83.

5. Dıraçoğlu D. Complementary-alternative medicine in rheumatoid arthritis. Rheumatism 2007;22(1):24-30.

6. Lee MS, Lee MS, Yang CY, et al. Use of complementary and alternative medicine by rheumatoid arthritis patients in Korea. Clin Rheumatol 2008;27(1):29-33.

7. Michalsen A. The role of complementary and alternative medicine (CAM) in rheumatologyit's time for integrative medicine. J Rheumatol 2013;40(5):547-9.

8.http://nccam.nih.gov/news/camstats/costsErişim Tarihi: 01.01.2014

9. Rao JK, Kroenke K, Mihaliak KA, Grambow SC, Weinberger M. Rheumatology patients' use of complementary therapies: results from a one-year longitudinal study. Arthritis Rheum 2003;49(5):619-25.

10. Wilson JW, Lieberman JD. The lure of unconventional therapy for rheumatic disease: how powerful is it? JAAPA 1999;12(11):69-74,7980,83-4.

11. Anderson DL, Shane-McWhorter L, Crouch $\mathrm{BI}$, Andersen SJ. Prevalence and patterns of alternative medication use in a university hospital outpatient clinic serving rheumatology and geriatric patients. Pharmacotherapy 2000;20(8):958-66.

12. Mikuls TR, Mudano AS, Pulley L, Saag KG. The association of race/ethnicity with the receipt of traditional and alternative arthritis-specific health care. Med Care 2003;41(11):1233-9.
13. Kaboli PJ, Doebbeling BN, Saag KG, Rosenthal GE. Use of complementary and alternative medicine by older patients with arthritis: a population-based study. Arthritis Rheum 2001;45(4):398-403.

14. Ramsey SD, Spencer AC, Topolski TD, Belza B, Patrick DL. Use of alternative therapies by older adults with osteoarthritis. Arthritis Rheum 2001;45(3):222-7.

15. Jordan JM, Bernard SL, Callahan LF, Kincade JE, Konrad TR, DeFriese GH. Self-reported arthritis-related disruptions in sleep and daily life and the use of medical, complementary, and self-care strategies for arthritis: the national survey of self-care and aging. Arch Fam Med 2000;9(2):143-9.

16. Kajiyama $H$, Akama $H$, Yamanaka $H$, et al. One third of Japanese patients with rheumatoid arthritis use complementary and alternative medicine. Mod Rheumatol 2006;16(6):355-9.

17. Munstedt $K$, Harren $H$, von Georgi $R$, Hackethal A. Complementary and alternative medicine: comparison of current knowledge, attitudes and interest among German medical students and doctors. Evidence-Based Complementary and Alternative Medicine 2011;2011(10):790951.

18. Ramos-Remus $C$, Watters CA, Dyke L, Suarez-Almazor ME, Russell AS. Assessment of health locus of control in the use of nonconventional remedies by patients with rheumatic diseases. The Journal of Rheumatology 1999;26(11):2468-74.

19. Breuer GS, Orbach H, Elkayam O,et al. Use of Complementary and alternative medicine among patients attending rheumatology clinics in Israel. Isr Med Assoc J 2006;8(3):184-7. 